\title{
Streptococcus dysgalactiae
}

National Cancer Institute

\section{Source}

National Cancer Institute. Streptococcus dysgalactiae. NCI Thesaurus. Code C86905.

A species of Gram-positive, alpha- or beta-hemolytic bacteria in the order Lactobacillales.

The species is split into two subspecies, S. dysgalactiae subsp. dysgalactiae and S.

dysgalactiae subsp. equisimilis. 